\title{
A VOZ DA ENFERMAGEM NO ENFRENTAMENTO À COVID-19: CÍRCULO DE CULTURA VIRTUAL*
}

\author{
Carine Vendruscolo' \\ ORCID: 0000-0002-5163-4789
}

Denise Antunes de Azambuja Zocche"

ORCID: 0000-0003-4754-8439

Jeane Barros de Souza"II

ORCID: 0000-0002-0512-9765

Ivonete Terezinha Schulter Buss Heidemann ${ }^{\text {IV }}$ ORCID: 0000-0001-6216-1633

Arnildo Korbv

ORCID: 0000-0001-7333-0754

I,II, Universidade do Estado de Santa Catarina. Chapecó, Santa Cataina, Brasil.

"Universidade Federal da Fronteira Sul. Chapecó, Santa Catarina, Brasil.

$\checkmark$ Universidade Federal de Santa Catarina. Florianópolis, Santa Catarina, Brasil.

1," Membros do Departamento Científico de Enfermagem na Atenção Básica-ABEn Seção SC

Autor Correspondente: Carine Vendruscolo

E-mail: carinevendruscolo@udesc.br

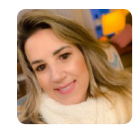

Como citar:

Vendruscolo C, Souza JB, Zocche DAA Heidemann ITSB, Korb A. A voz da enfermagem no enfrentamento à covid-19: círculo de cultura virtual. In: Teodósio SSS, Leandro SS (Orgs.).

Enfermagem na atenção básica no contexto da COVID-19. 2.ed.rev. Brasília, DF: Editora ABEn, 2020.

p. 67-72. (Série Enfermagem e Pandemias, 3). https://doi.org/10.51234/aben.20.e03.c10

\section{INTRODUÇÃO}

"O surto viral pulveriza este senso comum e evapora a segurança de um dia para o outro. Sabemos que a pandemia não é cega e tem alvos privilegiados, mas mesmo assim cria-se com ela uma consciência de comunhão planetária, de algum modo democrática. A etimologia do termo pandemia diz isso mesmo: todo o povo. A tragédia é que neste caso a melhor maneira de sermos solidários uns com os outros é isolarmo-nos uns dos outros e nem sequer nos tocarmos. É uma estranha comunhão de destinos. Não serão possíveis outras?"(1).

A humanidade vivencia a epidemia do coronavírus, como uma crise jamais imaginada, em plena segunda década do século XXI. Em metrópoles como São Paulo, Brasil, observa-se a discrepância entre pessoas vivendo em condições favoráveis para o enfrentamento da epidemia e, ao mesmo tempo, outras em situações bastante insalubres, em termos de condições básicas de vida. O agravamento das iniquidades produzidas por estas situações desiguais são só um, dentre os efeitos danosos causados pela doença Coronavirus Disease 2019 (COVID-19), que evolui com rapidez, esgotando a capacidade de resposta dos sistemas de saúde, em diversos países do mundo, tornando-se um grave problema de saúde pública mundial(2). No sul do país, embora em condições não tão precárias, enfermeiros têm liderado este enfrentamento, mediante estratégias e tomadas de decisões, junto às Secretarias Municipais, Hospitais e demais serviços da Rede de atenção à Saúde, demonstrando um protagonismo profissional nas dimensões assistencial e gerencial do cuidado.

Em dezembro do ano de 2019, depois de casos sintomáticos registrados em Wuhan, na China, foi descoberto este novo vírus da família coronavirus, denominado Severe

* Uma versão ampliada, e sob outra ótica, deste capítulo está em avaliação por periódico científico da área de enfermagem. 
Acute Respiratory Syndrome (SARS-CoV-2). O vírus causa a COVID-19, responsável por infecções respiratórias em seres humanos, permeadas por sintomas que variam de leves a graves e que se intensificam com a presença de comorbidades ${ }^{2}$. No início do ano de 2020, com a enfermidade amplamente disseminada em diversos continentes, a Organização Mundial da Saúde (OMS) enfatiza a sua seriedade e determina situação de pandemia, o que repercutiu no Brasil, em condutas de contenção, determinadas pelo Ministério da Saúde (MS), que definiu a quarentena como medida restritiva para a aglomeração de pessoas, a fim de diminuir a propagação do vírus.

Em meio à crise, um fenômeno chama a atenção: a mobilização coletiva de enfermeiros, evidenciando sentimentos e ações solidárias, mesmo afastados fisicamente, como bem colocou Santos ${ }^{1}$, no trecho que destacamos no início deste capítulo. $O$ autor questiona se seriam possíveis, então, outras comunhões desta natureza, em meio a tragédias. A fim de refletir sobre este e outros aspectos, este capítulo tem como objetivo relatar a experiência vivenciada por enfermeiras na linha de frente do combate à COVID-19, sobre os desafios do momento pandêmico, justamente em meio à Campanha para a valorização da enfermagem (Campanha Nursing Now), lançada em 2018 e que se encerra em 2020, pelo Conselho Internacional de Enfermeiras, OMS) e UK All Party Parliamentary Group on Global Health do Reino Unido. No Brasil, a Campanha se dissemina em todas as regiões do país, ampliando a visibilidade e o potencial da enfermagem, nos diferentes cenários de atuação.

Ao refletir sobre este fenômeno, pesquisadores de instituições públicas, no sul do país, reuniram de forma virtual, um grupo de enfermeiras que encontravam-se na linha de frente, em pleno combate à COVID-19. A partir da revelação da profissão como destaque neste enfrentamento e, considerando o ano em que, justamente, se comemora o bicentenário do nascimento de Florence Nigthingale, precursora da enfermagem moderna, por meio da Campanha Nursing Now, realizou-se um Círculo de Cultura virtual com enfermeiras, estudantes e egressas de um Mestrado Profissional em Enfermagem na Atenção Primária à Saúde, com o propósito de provocar o diálogo e a reflexão sobre os seus desafios, nesse contexto.

\section{Dando voz à enfermagem em meio à pandemia: os ruídos que emergem da ciência, da política e dos sentimentos}

O Círculo de Cultura é um método que foi idealizado pelo educador brasileiro e cientista social Paulo Freire. Freire apostava no diálogo como uma necessidade existencial e uma condição básica para o conhecimento. Ele acreditava que o ato de conhecer se desenvolve a partir de um processo social, mediado pelo diálogo, ou seja, é por meio da comunicação dialógica que se obtém a compreensão do significado social dos temas em discussão, o que provoca a tomada de consciência sobre a realidade. $O$ diálogo ocorre na comunicação entre os participantes, a partir de um encontro, que se realiza na práxis, ou seja, na ação com reflexão, e se fundamenta no compromisso com a transformação social ${ }^{(3)}$.

O Círculo se caracteriza por um grupo de pessoas com interesses semelhantes, que dialoga sobre situações de vida e problemas comuns, refletindo, coletivamente, sobre uma percepção mais profunda sobre a realidade 3 . O método de Freire, portanto, advém da pedagogia crítico-reflexiva e se expressa por meio da problematização, com vistas a promoção da aprendizagem significativa sobre a realidade vivida.

Neste relato, o Círculo foi adaptado para um ambiente virtual, como cenário de aproximação dos participantes. Utilizou-se o aplicativo Zoom ${ }^{\circledast}$, mediante a utilização de computadores ou celulares com câmera. Foram convidadas para participar do Círculo de Cultura virtual, voluntariamente, enfermeiras egressas e mestrandas de um Programa de Pós graduação em Enfermagem (Mestrado Profissional em Enfermagem na Atenção Primária à Saúde), em uma universidade pública, no sul do Brasil. Concordaram em participar da atividade 15 enfermeiras, todas mulheres, quatro egressas e 11 estudantes das turmas em andamento, todas elas envolvidas, de alguma forma, no enfrentamento à COVID-19.

A enfermagem constitui a metade da força de trabalho em saúde e os enfermeiros são reconhecidos como os principais responsáveis pela coordenação das equipes, nos diferentes níveis de atenção à saúde. Nessa 
direção, uma das estratégias para investir na força de trabalho e valorizar o enfermeiro para o avanço da profissão é a aproximação entre as instituições de ensino e os serviços de saúde. Os Mestrados Profissionais constituem-se como iniciativas para a reorientação dos profissionais da saúde, com vistas a qualificar a assistência e consolidar o Sistema Único de Saúde (SUS). Essa modalidade de formação stricto sensu se destaca no Brasil, nos cenários que integram o ensino e o serviço na área da saúde, pois seu propósito é suprir as demandas sociais, políticas e econômicas, articuladas à qualificação de trabalhadores no serviço. Na área de enfermagem, habilita o profissional atuante nos cenários da prática para atividades técnico-científicas e de inovação, mediante a prática profissional avançada e transformadora de procedimentos e processos aplicados, por meio da incorporação do método científico ${ }^{(4)}$. O Mestrado em questão, tem foco na Atenção Primária à Saúde e, entre as estudantes, a maioria tem como cenário de atuação na prática profissional, Unidades Básicas de Saúde, desenvolvendo atividades nas dimensões assistencial, educativa e de gestão.

A experiência se desenvolveu em abril de 2020, em plena quarentena ocasionada pela COVID-19. Foi elaborado um guia prévio para a intervenção e agendado um momento em que todas pudessem acessar a mídia virtual. $\mathrm{O}$ encontro foi facilitado por duas professoras enfermeiras, envolvidas na coordenação do Mestrado Profissional. Posteriormente, os resultados contaram com o olhar e interpretação de outros dois professores com experiência na mediação de Círculos de Cultura.

O Círculo teve duração de duas horas e foi guiado pelo Itinerário de Pesquisa de Paulo Freire, cuja perspectiva pedagógica crítico-reflexiva se apoia no diálogo e em relações horizontalizadas, constituído por três etapas, interligadas entre si: (1) Investigação Temática; (2) Codificação e Descodificação; (3) Desvelamento Crítico(3).

Foi realizada uma analogia com o estetoscópio para percorrer as fases do Itinerário, conforme ilustração da Figura 1. Esse instrumento concreto é uma ferramenta de trabalho dos profissionais da área da saúde e suas três partes foram representativas das etapas do Itinerário de Pesquisa de Freire: Investigação Temática (diafragma), Codificação e Descodificação (tubo de condução) e o Desvelamento Crítico (hastes e olivas, que revelam finalmente o "diagnóstico").

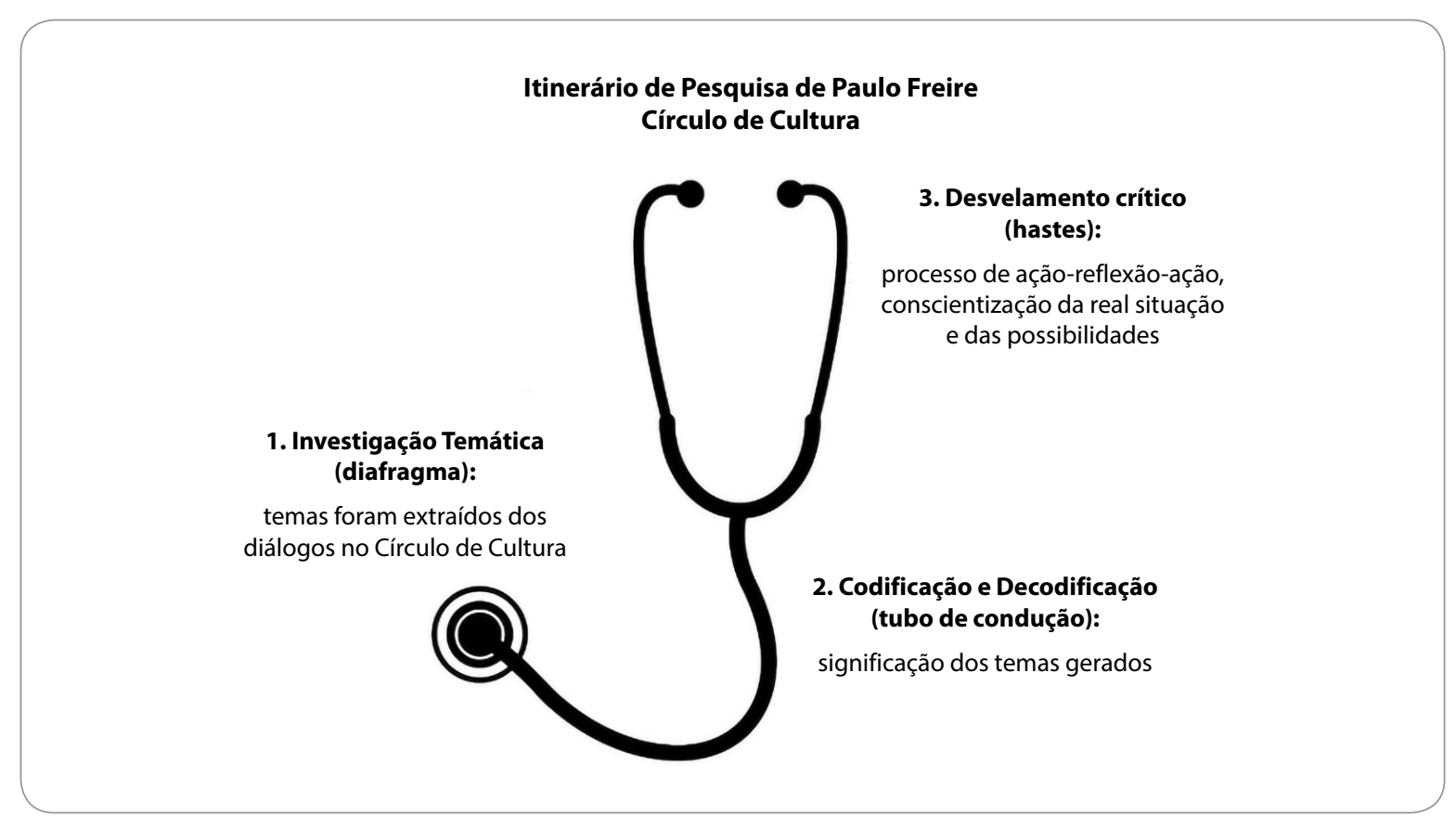

Fonte: adaptado pelos autores a partir de http://www.ultracoloringpages.com/pt/p/estetosc\%C3\%B3pio-desenho-para-colorir/535ee2985f95e14a7976e78def3e1b50 Figura 1 - Itinerário de Pesquisa de Paulo Freire: analogia com o estetoscópio 
Com a figura compartilhada em tela, as mediadoras refletiram com as participantes que este instrumento auxilia na ausculta dos indivíduos, para diagnóstico de diversas situações, representando o primeiro momento do Itinerário (Investigação Temática), com a parte do diafragma do estetoscópio que seria utilizada para ouvir as enfermeiras quanto aos seus sentimentos relacionados às repercussões da COVID-19. Para provocar o diálogo, foi utilizada a questão disparadora: que sentimentos as crises geradas pela COVID-19 despertam em você como profissional?

Na segunda etapa, que corresponde à Codificação e Descodificação, as mediadoras provocaram a reflexão a partir das respostas das enfermeiras, que levaram à identificação de que existem ruídos oriundos do diafragma e, para descodificá-los, é importante o tubo de condução, extraindo aquilo que é útil e necessário para o diagnóstico. As situações de crise geradas pela COVID-19, emergiram no diálogo, evidenciando a realidade. Assim se desenvolveu a codificação de uma situação existencial, por meio da sua representação com alguns elementos constitutivos, em interação( ${ }^{(5)}$.

Na etapa de Desvelamento Crítico da realidade, fase da Problematização ou Redução Temática, as enfermeiras foram estimuladas a desenvolver a consciência, por meio de conceitos. Os conceitos permitem exteriorizar a visão do mundo e a percepção sobre as situações limite e sobre a realidade, por elas vivenciada. Neste momento, é importante que o mediador reduza ao mínimo sua intervenção direta, durante o diálogo(3).

A partir da alusão com o estetoscópio, as mediadoras e as enfermeiras refletiram sobre o diagnóstico, elaborado a partir dos sons, ruídos e constatações ocasionadas pelo momento histórico ocasionado pela pandemia, lembrando que são as hastes e olivas que permitem desvelar o som que se deseja auscultar. Com esses elementos, mediante a exploração de evidências científicas, da experiência e vivências das enfermeiras, foram desveladas as reflexões preliminares, por meio da codificação objetiva, contemplando princípios da subjetividade interpretativa(5).

A dialogicidade do Círculo de Cultura virtual resultou em Temas Geradores, dentre os quais: "os ruídos que emergem da ciência, da política e dos sentimentos", que foi selecionado para discussão, neste capítulo.

Para as participantes, emergiram ruídos relacionados ao lugar da ciência e da política, neste contexto de pandemia. Elas problematizaram, nessa direção, as defesas de economistas, políticos e cientistas, que, em meio a contradições, deixam a população sem norte. No cenário brasileiro, para além da COVID-19, há um agravante para a população, representado pela situação política, que apresenta divergências de posicionamentos entre a presidência da república e a autoridade sanitária, o Ministério da Saúde ${ }^{(6)}$.

Com base nessa lógica, elas refletem a necessidade de que pesquisas respondam a desafios cotidianos dos serviços de saúde, que quando desenvolvidas, especialmente, no âmbito da Atenção Primária, produzam conhecimentos e, ao mesmo tempo, intervenções, por meio da criação de técnicas e tecnologias que possam impactar e transformar as práticas. Nessa perspectiva, o Mestrado Profissional as prepara e as convence de que o desenvolvimento de uma agenda de pesquisa e uma melhor gestão do conhecimento são elementos essenciais para abordar os Determinantes Sociais da Saúde, garantir o acesso a serviços de qualidade e a sua resolutividade, com vistas à consolidação do SUS e dos seus princípios. Para tanto, também é fundamental, incorporar a tecnologia e avaliar a eficácia das ações e dos programas implementados ${ }^{(7)}$.

No século XVIII, Jacques Rousseau questionou se haveria alguma relação entre a ciência e a virtude, que justificasse a substituição do conhecimento vulgar das pessoas sobre a vida, pelo conhecimento científico, produzido por poucos e inacessível à maioria. Dessa forma, indagou: "Contribuirá a ciência para diminuir o fosso crescente na nossa sociedade entre o que se é e o que se aparenta ser, o saber dizer e o saber fazer, entre a teoria e a prática?" "(8). Naquela época, Rousseau respondeu "não" para essas perguntas. O que a enfermagem responderia hoje? A despeito da ciência, da qual trata o texto, na atualidade não necessariamente compreendida como única verdade e que, juntamente com a moral e a ética, poderia nortear a tomada de decisões seguras, parece que é possível investir na relação entre a ciência e os valores/virtudes, e que a enfermagem pode contribuir nessa direção. Após 200 anos, como produtos e protagonistas das transformações produzidas pela ciência, 
posicionados na linha de frente no combate à COVID-19, os profissionais demonstram que, mesmo com a escassez de Equipamentos de Proteção Individual (EPI) (luvas, máscaras cirúrgicas, óculos de proteção ou proteção facial e batas cirúrgicas, itens para procedimentos específicos, respiradores e aventais(5), somada a sobrecarga de trabalho, relacionada à falta de pessoal e aumento do número de pessoas contaminadas pelo SARS-CoV-2, são capazes de somar esforços técnicos e científicos aos valores humanos, como a solidariedade e o afeto, no cuidado às vítimas.

Durante a situação de crise, sentimentos afloram entre as enfermeiras, seja pelo medo de não superar a crise, como também, pelo medo de os seus familiares contraírem o vírus. Elas percebem, nos diferentes municípios que atuam, as diferenças sócio-econômico-culturais e suas repercussões sobre as possibilidades (ou não) de cuidado adequado aos acometidos pela doença. Sofrem com as iniquidades que se evidenciam, nesse contexto.

Os profissionais de saúde, que estão atuando diretamente, no combate à COVID-19, demonstram cansaço físico e mental, ansiedade e medo de colegas serem contaminados pelo vírus SARS-CoV-2, bem como, sofrem pelo risco de infecção e a possibilidade de transmitir para familiares ${ }^{(6)}$. Envoltas por tais sentimentos, as participantes desvelaram que vem à tona uma sensação de "dever cumprido" (ou necessidade de cumprir o dever), devido a esse papel que assumem, de proteger a família e a equipe de saúde. Elas argumentaram que a enfermagem tem se mostrado solidária, enquanto equipe, incluindo colegas de outras profissões para a tomada de decisão, em meio à pandemia. Da mesma forma, as pessoas são solidárias, emergindo algo que, de certa forma, estava oculto na sociedade, nos últimos tempos, em que as disputas políticas ganhavam mais destaque no Brasil. Todavia, por vezes, sentem-se sobrecarregadas, ao tomar para si atribuições que poderiam ser assumidas por outros profissionais da equipe.

O trabalho do enfermeiro no campo da APS se pauta na socialização de práticas de saúde consideradas comuns e pertinentes a qualquer categoria profissional, articulando-se com outros profissionais. Contudo, poucas categorias se abrem para essa nova forma de realizar o trabalho na saúde, restringindo-se, quase sempre, ao seu núcleo disciplinar. Isso representa um prejuízo para o enfermeiro que, no cenário da APS, apresenta uma prática disseminada, em que prioriza as ações do campo da saúde coletiva em detrimento das ações nucleares da profissão, distanciando-se do seu fazer específico que possa representar um referencial identitário(9).

Por fim, as enfermeiras relembraram sua precursora, Florence Nightingale, e buscaram inspiração no seu legado, ao comparar a situação vivenciada na atualidade à história da enfermagem moderna, que justamente, em plena pandemia da COVID-10, em 2020, comemora seu bicentenário. Florence foi objeto de pesquisa para estudiosos da saúde, pois, indiscutivelmente, contribuiu para o desenvolvimento da saúde e, sobretudo, da enfermagem, superando as fronteiras da ciência, da política e dos sentimentos que suscitaram na sua época. Nascida em Florença, Itália, em 1820, ela utilizou a informação estatística para estabelecer a conduta das enfermeiras sob a sua gerência, influenciando a ação política e governamental na persuasão de autoridades, sobre a necessidade de redução das taxas de mortalidade, mediante a adoção de práticas de higiene, durante a Guerra da Criméia, em $1854^{(10)}$.

À luz das considerações tecidas sobre os desafios vivenciados por enfermeiras que enfrentam a COVID-19 em uma região do sul do Brasil, foi perceptível a reflexão destas sobre o seu papel como profissionais, unindo as tecnologias da ciência moderna com a sabedoria da vida, neste momento pandêmico. $O$ cuidado de enfermagem, fundamentado na moral, na ética, na cultura e na política, envolve também, sentimentos como afeto e solidariedade, expressando assim, o "saber-fazer" da profissão, neste contexto histórico.

Compreende-se a relevância da enfermagem, sobretudo no âmbito da Atenção Primária à Saúde, ao comportar-se como protagonista, mediante a possibilidade de efetuar cuidados para a clínica, na prevenção e na promoção da saúde. A profissão pode fomentar (e tem fomentado) na população a autonomia para adoção de estilos de vida saudáveis e o empoderamento individual e coletivo, além da compreensão de que outras doenças também, são invisíveis e carecem de uma compreensão científica. 


\section{CONSIDERAÇÕES FINAIS}

O Círculo de Cultura virtual promoveu um encontro, que se realizou na práxis, ao estimular as enfermeiras à ação, a partir da reflexão. Elas assumiram o compromisso com a transformação social, no momento em que desvelaram um novo olhar sobre a sua prática profissional e refletiram sobre suas condutas, no enfrentamento a COVID-19. Nos diálogos, emergiram sentimentos e reflexões críticas sobre os desdobramentos da crise, comparados à ruídos do estetoscópio, os quais emergem de questões científicas e políticas, que reverberaram com esta vivência. Tudo isso, somado aos sentimentos de medo, proteção e dever, colocaram em evidência seu empoderamento, enquanto enfermeiras, e elas se perceberam como cuidadoras, refletindo, como se fosse um espelho, a imagem de Florence Nightingale no passado, em situações semelhantes, com desfechos ainda, incertos.

As iniquidades geradas pela pandemia, mais do que nunca, fazem pensar nas diferenças, nas possibilidades, por vezes injustas, de prevenção e cura entre as diferentes classes sociais, entre os gêneros, raças/etnias. As enfermeiras, ao questionarem sua prática profissional no contexto pandêmico, resgataram o princípio da equidade, que pode contribuir para promover o respeito à diversidade e garantir a integralidade no Sistema Único de Saúde.

\section{REFERÊNCIAS}

1. Santos BS. A cruel pedagogia do vírus. [Internet]Coimbra: Almedina. [acesso 22 jun 2020]2020. Disponível em: https:// www.cpalsocial.org/documentos/927.pdf

2. OMS. Organização Mundial da Saúde. Coronavirus disease (COVID-19) outbreak: rights, roles and responsibilities of health workers, including key considerations for occupational safety and health [Internet]. 18 March 2020 [acesso 22 jun 2020]. Disponível em: https://www.who.int/docs/default-source/coronaviruse/who-rights-roles-respon-hw-covid-19. pdf?sfvrsn=bcabd401_0

3. Freire P. Pedagogia do oprimido. 64ª ed. Rio de Janeiro: Paz e Terra; 2017.

4. National Nursing Centers Consortium (NNCC). Global Advanced Practice Nursing Symposium. United State of America [Internet] 2014 [acesso 22 jun 2020]. Disponível em: http://www.nncc.us/images_specific/pdf/GlobalAPNSymposiumFIN AL.pdf

5. Heidemann ITSB, Dalmolin IS, Rumor PCF, Cypriano CC, Costa MFBNA, Durand MK. Reflections on Paulo Freire's research itinerary: contributions to health. Texto Contexto Enferm. [internet]. 2017[acesso 22 jun 2020];26(4):1-8. Disponível em: https://www.scielo.br/pdf/tce/v26n4/en_0104-0707-tce-26-04-e0680017.pdf

6. Silva, M.R., Pires, G.L., Pereira, R.S. O necroliberalismo, Bolsonaro'vírus mental' e a pandemia da COVID-19 como casos de saúde pública: o real resiste? Editorial. [Internet]. Motrivivência. 2020 [acesso 22 jun 2020];32(61):1-18. Disponível em: https://periodicos.ufsc.br/index.php/motrivivencia/article/view/2175-8042.2020e72755

7. Pan American Health Organization. Strategy for universal access to health and universal health coverage. Proceedings of the 53rd Directing Council (CD53/5, Rev. 2) [Internet] Washington DC. 2014 [acesso 10 jun 2020]. https://www.paho.org/ hq/dmdocuments/2014/UHC-ConsultationsCD53English.pdf

8. Rousseau J-J. Discours sur les Sciences et les Arts, in Oeuvres Completes. vol. 2, Paris, Seuil, 1971, p. 52 e segs.

9. Fernandes MC, Silva LMS, Silva MRF, Torres RAM, Dias MSA, Moreira TMM. Identidade do enfermeiro na Atenção Básica: percepção do "faz tudo". Rev Bras Enferm [Internet]. 2018;71(1):154-9. [acesso 22 jun 2020]. Disponível em: https://www. scielo.br/pdf/reben/v71n1/pt_0034-7167-reben-71-01-0142.pdf

10. Martins DF, Benito LAO. Florence Nightingale e as suas contribuições para o controle das infecções hospitalares. Universitas: Ciências da Saúde [internet]. 2016;14(2):153-166. [acesso 10 mai 2020]. Disponível em: https://www. publicacoesacademicas.uniceub.br/cienciasaude/article/view/3810/3274 